\title{
A COMPETIÇÃO DE JUDÔ DOS MAIS JOVENS: O DISCURSO DOS RESPONSÁ VEIS PELAS AGREMIAÇÕES
}

Fabiano Filier Cazetto

Paulo Cesar Montagner

Pablo Christiano Lollo

\section{Resumo}

O Judô enquanto uma prática competitiva institucionalizada é o foco deste estudo. A pesquisa teve como instrumentos questionários/entrevistas, que foram aplicadas aos responsáveis pelas agremiações em umas das delegacias do Estado de São Paulo. O tratamento dos dados foi através de análise do conteúdo do discurso. Os resultados confirmam a hipótese inicial de que o Judô é um elemento de múltiplos significados, sendo visto principalmente como esporte e filosofia de vida. $\mathrm{O}$ discurso dos entrevistados indica que a competição é considerada como algo positivo e educacional. Os mais jovens não são "lembrados" ao descrever esse fenômeno e pouco se reflete sobre um modelo de competição específico. Incoerências podem decorrer desse quadro tais como as relatadas nas entrevistas (deterioração e cobrança). É necessário pensar um modelo de competição específico para os mais jovens, do ponto de vista educacional.

\section{Palavras-Chave}

Artes marciais; Sociologia; Criança.

\section{THE YOUNG ONES JUDO COMPETITION: THE TEAMS' RESPONSIBLE SPEECH}

Fabiano Filier Cazetto

Paulo Cesar Montagner

Pablo Christiano Lollo

\begin{abstract}
This study is about the young ones in Judo competition. The team's responsible respond to questionnaires and interviews. The data treatment has been made by discourse analysis. The results indicate that Judo is seen as a sport and a life philosophy between other means, but very few speeches contain concerns about the young ones and the competition model. Problems may happen in this situation, some are related in the interviews (deterioration and pressure). The young ones need a specific educational competition model.
\end{abstract}

\section{Key-Words}

Martial Arts; Sociology; Child. 


\section{INTRODUÇÃO}

O Judô é um elemento da cultura corporal de múltiplos significados (CAZETTO, 2004a), podendo "aparecer" em diversos "cenários": clubes, academias e escolas. As pessoas em sociedade atribuem diversos significados à sua prática: saúde, condicionamento físico, esporte, arte marcial, divertimento, educação etc.

A competição, no esporte, é apenas um dos significados que pode ser atribuído à sua prática em sociedade, porém, este é um elemento presente e significativo na formação de diversos jovens em nossa sociedade. Isso posto, o presente artigo buscará discutir a prática institucionalizada do Judô tendo como foco prioritário seus aspectos da competição para jovens praticantes. O Judô enquanto uma prática competitiva institucionalizada é o foco desse estudo.

Elias (1993) ajuda-nos a pensar no "momento atual" e nos fatores sociais que envolvem os fenômenos, no nosso caso, o Judô enquanto uma modalidade esportiva. Brohm (1982) apoia-se em um referencial marxista para efetuar a crítica ao esporte. Contestando seus significados, critica a visão do esporte como entidade neutra, entende-o como imerso em fatores sociais; embasado em seu referencial peculiar: pensa no fator social do conflito de classes.

Dessa maneira o Judô é visto como uma construção social em certo "momento" histórico, envolvida por inúmeros fatores sociais. Os sujeitos que a constroem não são atemporais e alheios a sua sociedade, mas sim culturalmente imersos em suas práticas e seus significados. Particularmente é necessário destacar o avançado processo de esportivização, espetacularização e mundilização do Judô. Neste sentido existe certo processo de monopólio, um modelo a ser seguido, particularmente pautado pela dominação midiática construída essencialmente pela classe dominante.

Este trabalho pretende estudar as condições sociais de construção do Judô dos mais jovens (6 aos 16 anos). Seu foco principal são as competições. Para isso, lançamos mão de questionários/entrevista qualitativa aos responsáveis pelas agremiações no âmbito institucionalizado da modalidade na Federação Paulista de Judô, tentando estabelecer uma "imagem”, uma concepção, sobre alguns elementos presentes nesse cenário. 


\section{MÉTODO}

Toda a pesquisa seguiu os aspetos éticos necessários e foi aprovada e supervisionada pelo Comitê de Ética em pesquisa da Faculdade de Ciências Médicas da Universidade Estadual de Campinas (Número do projeto: 410/2006).

\section{SUJEITOS DO ESTUDO}

O Estudo foi restrito a sujeitos adultos, de ambos os sexos, capazes de responder voluntariamente aos questionários não atingindo nenhuma das “populações especiais” descritas nas resoluções 196/96” .

Esta incursão a campo corresponde a uma fase específica de um conjunto de investigações inicialmente desenvolvidas como projetos de iniciação científica financiados em dois momentos pelo CNPq (Conselho Nacional de Desenvolvimento Científico e Tecnológico) e mais tarde tendo continuidade como um projeto de mestrado.

Nesta fase optou-se pela construção de um instrumento direcionado a voluntários adultos, destacando que a construção da competição dos mais jovens é feita eminentemente pelos adultos.

Foram entrevistados os responsáveis pelas agremiações de uma das 15 delegacias do estado de São Paulo. Somente foram incluídos sujeitos voluntários através de métodos aceitos e acordados com os organizadores da reunião em plena concordância com as normas por eles estabelecidas.

\section{ORGANOGRAMA DO JUDÔ}

Para melhor compreensão de nossa pesquisa é necessário entender um pouco de como se organiza o Judô. A organização institucional do Judô é feita na Federação Internacional de Judô (FIJ), através da divisão em uniões. O Brasil faz parte da União Pan-Americana de Judô (UPJ), através da Confederação Brasileira de Judô (CBJ), que, por sua vez, é dividida em federações estaduais ${ }^{2}$.

A Federação Paulista de Judô (FPJ) é dividida em 15 delegacias regionais ${ }^{3}$. Diretamente ligados à

\footnotetext{
${ }^{1}$ Para maiores informações sobre resoluções sobre aspectos éticos, acessar http://www.fcm.unicamp.br/pesquisa/ resolucoes.php.

2 Atualmente existem também as Ligas, que não foram foco do estudo.

${ }^{3}$ Para maiores informações sobre a organização do Judô Mundial, consulte: www.ijf.org. Para maiores informações sobre a organização do Judô no Brasil, consulte: www.cbj.com.br. Para maiores informações sobre a organização do Judô no estado de São Paulo, consulte: www.fpj.com.br.
}

Conexões: revista da Faculdade de Educação Física da UNICAMP, Campinas, v. 8, n. 2, p. 159-173, maio/ago. 2010. 
Federação Paulista estão os responsáveis pelas agremiações que, através de voto, escolhem periodicamente seus dirigentes. Sendo assim, os responsáveis têm influência não só sobre sua própria agremiação, como também sobre as delegacias e sobre o Estado.

O número de responsáveis varia em cada delegacia, tomando como referência a última lista publicada pela federação em 2009, teríamos aproximadamente 18,7 agremiações por delegacia (281 agremiações/15 delegacias). Porém esse número é aproximado, pois sofre variações entre os anos, entre diferentes delegacias e uma mesma pessoa pode ser responsável por mais de uma agremiação.

\section{PILOTO DO QUESTIONÁRIO/ENTREVISTA}

Primeiramente foi construído um questionário/entrevista piloto sobre Judô e Competição dos mais Jovens. Utilizamos como material, um caderno de anotações, uma caneta esferográfica, um gravador de voz, questionários/entrevistas impressos e termo de consentimento livre e esclarecido. A preocupação central para formulação desse método era atender as necessidades operacionais para obtenção de dados junto aos "personagens" que constroem a competição da maneira que ela é.

O público-alvo para o questionário piloto foram alunos adultos de Judô de uma equipe de treinamento. Seu recrutamento foi feito em uma aula em que o professor responsável pela equipe pediu para que os voluntários apresentassem-se ao local de entrevista.

\section{APLICAÇÃO DO QUESTIONÁRIO/ENTREVISTA}

Nesta fase, foi estabelecido contato, via correio eletrônico, com o delegado regional, obtendo-se previamente sua permissão para aplicar o instrumento de pesquisa, que foi aplicado no dia 28 de janeiro de 2007, pouco antes do começo a reunião.

No começo da reunião, o delegado regional apresentou o pesquisador e pediu que os voluntários apresentassem-se, um a um, para a entrevista. Nesse momento, lhes foi perguntado se poderiam dispor de aproximadamente cinco minutos para responder ao questionário e, no caso afirmativo, esclarecimentos sobre as questões éticas e sobre a natureza da pesquisa.

Após esclarecer todas as dúvidas e entregar o termo de consentimento de participação da pesquisa, aplicou-se o questionário e logo após, a entrevista. Todos os entrevistados tiveram acesso ao telefone para 
eventuais denúncias sobre a pesquisa. Foi disponibilizado, também, o contato para obtenção dos resultados e acesso a pesquisas anteriores.

\section{INSTRUMENTOS DO ESTUDO}

Os termos e métodos que embasaram a construção dos instrumentos dessa fase da pesquisa foram definições contidas em Lakatos e Markoni (1995).

O questionário estruturado caracterizou-se por um conjunto de questões pré-definidas sobre itens que possibilitassem descrever a amostra segundo características consideradas relevantes para a pesquisa (sexo; idade; profissão; tempo de prática; e faixa). Optou-se por aplicar essas perguntas na forma escrita, pela facilidade de transcrição e preenchimento de respostas mais curtas dessas perguntas.

Entrevista: na segunda parte dessa fase da pesquisa, optou-se por entrevistas áudio gravadas. As perguntas foram feitas através de um questionário estruturado. Optamos pela entrevista devido à extensão das respostas que demandariam mais tempo para ser respondidas de forma escrita.

\section{TIPO DE ESTUDO E TRATAMENTO DOS DADOS}

A técnica empregada para a interpretação dos dados foi:

- pré-análise dos dados obtidos (primeira leitura dos dados do questionário e escutar as gravações das entrevistas);

- Levantamento das categorias a serem analisadas;

- Levantamento das frequências em cada uma das categorias;

- Revisão das frequências;

- Construção de gráficos;

- Reflexões e Interpretações sobre os dados obtidos.

A análise dos dados dependeu da leitura das transcrições e revisão do áudio, foi apresentado um panorama geral dos resultados, como sugere Bardin (2002). Com as categorias definidas, levantamos as frequências dos posicionamentos segundo cada categoria. Esse processo nos apresentou valores numéricos, o que facilitou interpretações e reflexões posteriores.

Bardin (2002) cita a análise de conteúdo como um método de traduzir numericamente dados coletados por instrumentos abertos. Trabalharmos anteriormente (CAZETTO et al., 2006) baseados no método 
adaptado por Ritz (2000), que constrói instrumentos fechados quantitativos através de informações coletadas de forma qualitativas (reuniões com diversos profissionais que tem conhecimentos sobre o objeto de estudo), sua metodologia fundamentou os instrumentos de pesquisa.

Através de estudos preliminares (CAZETTO, 2004a; CAZETTO; PAES 2004b; CAZETTO; PAES, 2005; CAZETTO et al., 2006) e do referencial teórico, foi construído um instrumento preliminar e que foi testado no piloto da pesquisa. Após as correções necessárias, reaplicamos o questionário para a obtenção de dados.

\section{CONSTRUÇÃO E INTERPRETAÇÃO GRÁFICA}

Os gráficos aqui representados mostram o posicionamento dos entrevistados com relação ao total de entrevistas em cada categoria analisada em cada uma das perguntas, podendo ser positivo ou negativo ou nulo.

Cada uma das entrevistas que contenham uma resposta positiva ou negativa com relação a uma categoria analisada representa pontuação de um (1) ou menos um (-1) respectivamente dividido pelo número total de entrevistas.

Uma única resposta pode enquadrar-se em mais do que uma categoria, porém, não pode representar, em uma mesma categoria, um valor positivo e negativo ao mesmo tempo. Nesse caso o valor é nulo.

Optamos por representar graficamente apenas as categorias analisadas que tiveram freqüência igual ou superior a $25 \%$, de maneira a simplificar e limitar a quantidade de informações contida em cada gráfico.

\section{RESULTADOS}

Foram entrevistados 13 voluntários adultos. As respostas indicam que a amostra é constituída, em sua maioria por homens $(76,9 \%)$, maiores de 30 anos $(85 \%)$, com considerável experiência e conhecimento no Judô (em média 29,35 anos de prática). Apesar do número reduzido de entrevistados, estes representam aproximadamente $70 \%$ da média de responsáveis por delegacia. Sua relevância se dá também por sua importância política no "cenário" competitivo.

\section{O QUE É O JUDÔ PARA VOCÊ?}




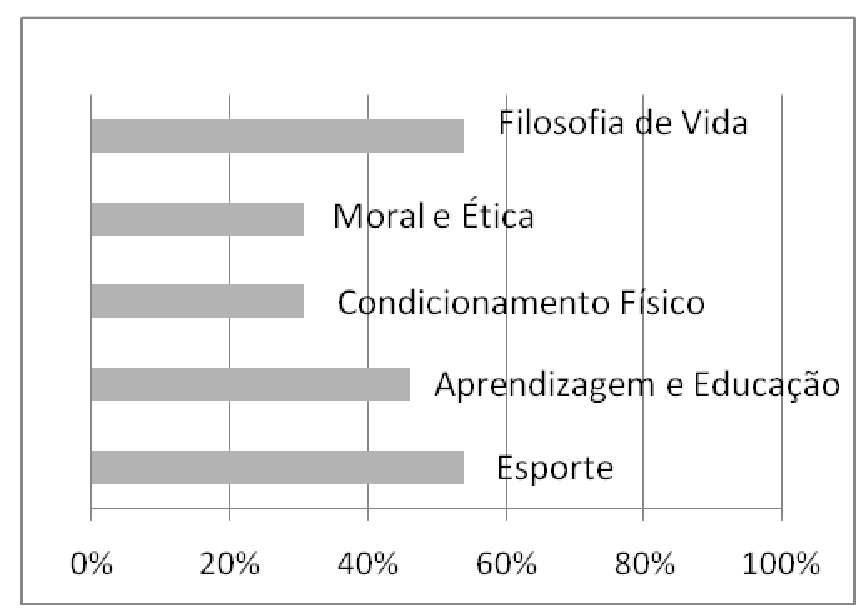

Gráfico 1 - O que é o Judô para você?

Os resultados apontam para uma frequência de respostas de 53,85\% dos entrevistados caracterizando o Judô como uma atividade esportiva. O mesmo acontece com filosofia de vida. Logo em seguida, temos aprendizagem e educação com 46,15, e 30,77\% das respostas para ética e moral, assim como condicionamento físico.

\section{NA SUA OPINIÃo, COMO É A COMPETIÇÃo HOJE NA SUA REGIÃo E NO ESTADO DE SÃO PAULO?}

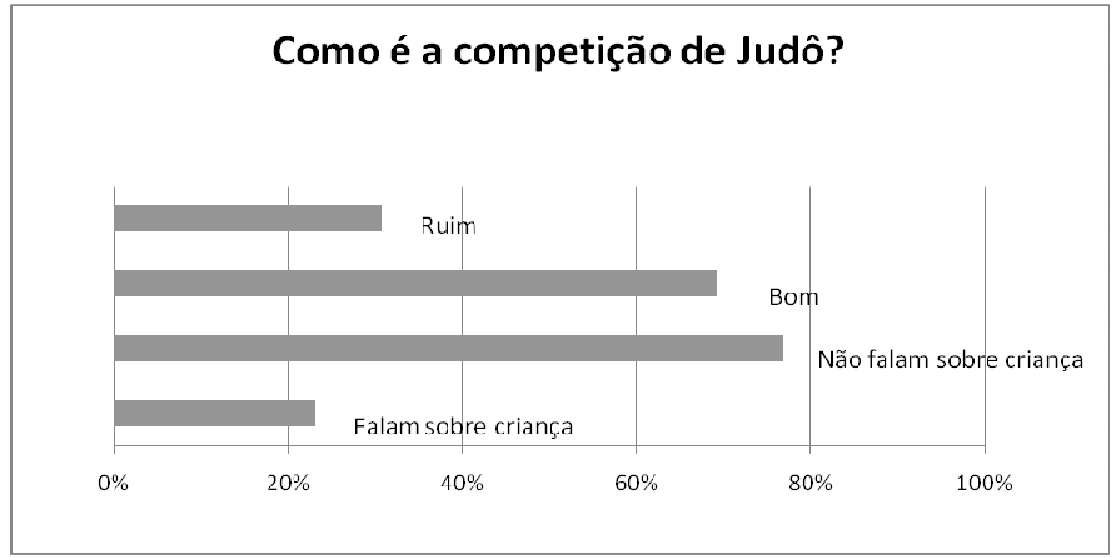

Gráfico 2 - Na sua opinião, como é a competição hoje na sua região e no estado de São Paulo.

Ao descrever a competição de Judô, a maior parte dos entrevistados não cita os mais jovens (76,92\% das respostas).

Todos os entrevistados opinaram sobre a competição ser algo positivo ou negativo, sendo que a maioria posiciona-se positivamente $(69,23 \%)$ 


\section{NA SUA OPINIÃO, DEVERIA EXISTIR ALGUMA MUDANÇA NAS COMPETIÇÕES DE JUDÔ?}

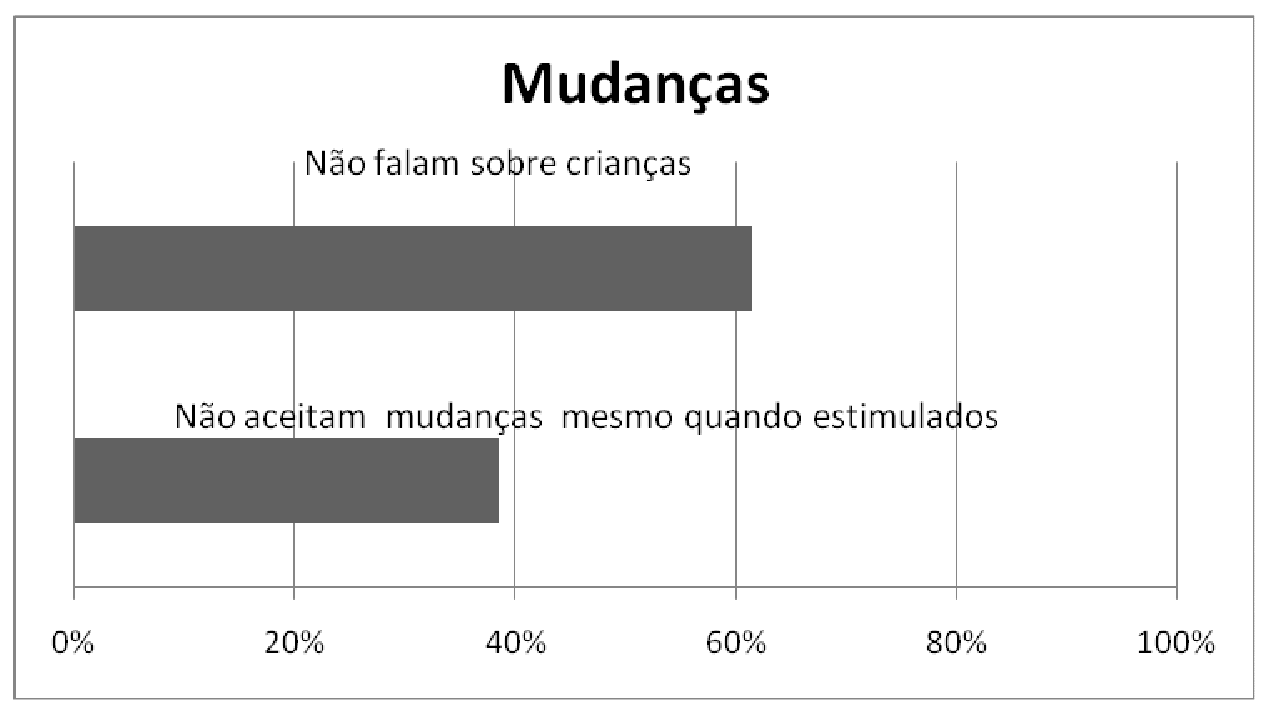

Gráfico 3 - Na sua opinião, deveria existir alguma mudança nas competições de Judô?

Mesmo quando estimulados a refletir sobre possíveis mudanças, ainda temos 38,46\% que declaram que não acreditam nelas. Apenas 30,77 dos entrevistados fez alguma colocação sobre os mais jovens, porém, se compararmos com aqueles que acreditam em mudanças, teríamos $50 \%$ das pessoas das que acreditam em mudanças citando alguma questão relacionada com os mais jovens.

PARA QUE SERVEM, QUAL A FINALIDADE, DAS COMPETIÇÕES DE JUDÔ?

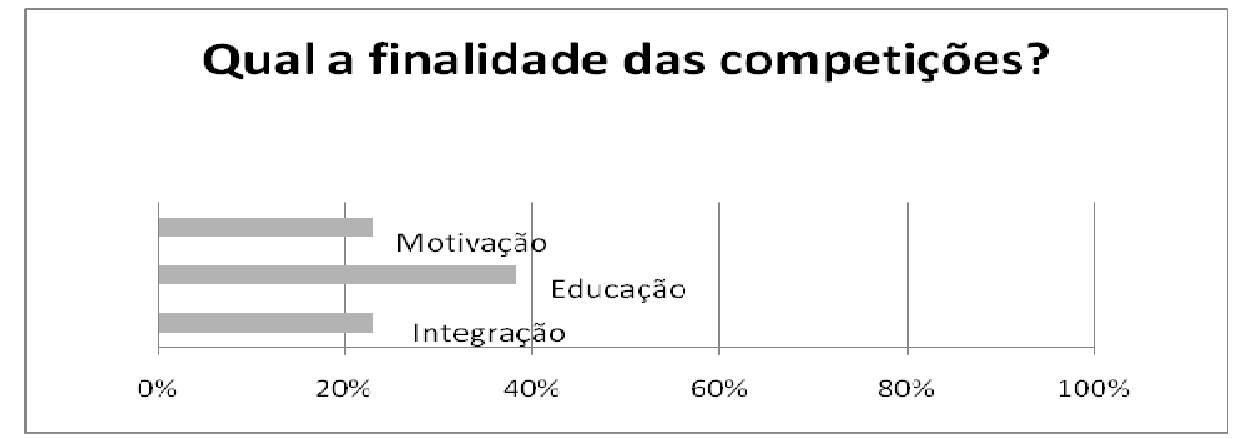

Gráfico 4 - Qual a finalidade das competições de Judô? 
Ao descrever os objetivos da competição, apenas $15 \%$ dos entrevistados diferenciaram os objetivos da competição para as crianças e a competição em geral ou para os adultos, enquanto que $77 \%$ não fizeram qualquer diferenciação.

A frequência de respostas de entrevistados que descreveram questões ligadas aos atletas foi de 69,23\%, apenas $46,15 \%$ dos entrevistados descreveram questões externas aos atletas.

Os dados indicam ainda 38,64\% das respostas relacionando a competição à aprendizagem e educação e 23,08\% relacionando com meio de integração social. O mesmo número se referiu à competição como meio de motivação.

\section{NA SUA OPINIÃO, COMO É A COMPETIÇÃO DOS MAIS JOVENS, HOJE, NA SUA REGIÃO E NO ESTADO DE SÃO PAULO?}

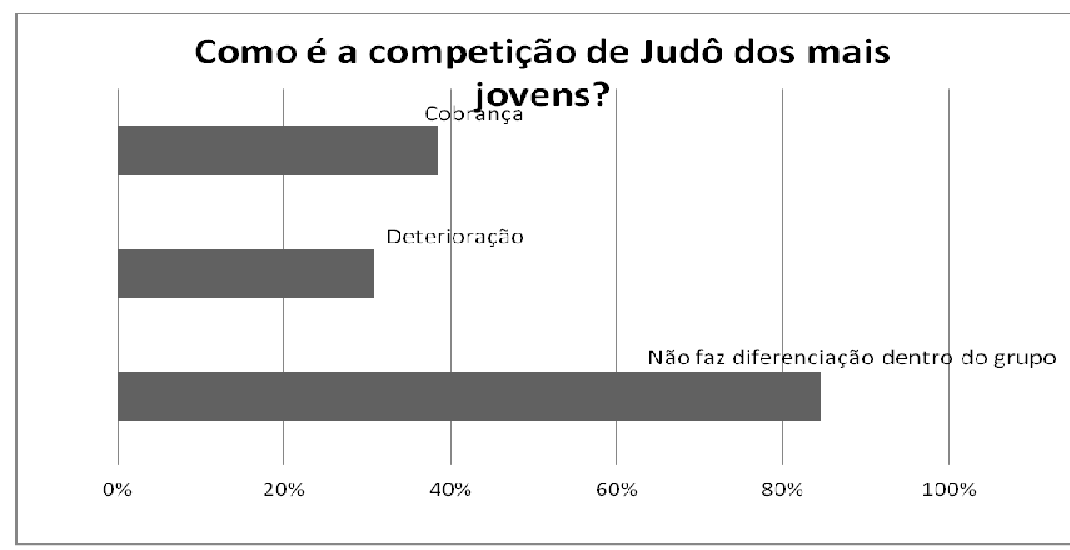

Gráfico 5 - Na sua opinião, como é a competição dos mais jovens, hoje, na sua região e no estado de São Paulo?

Ao descrever a competição, 84,61\% dos entrevistados não fazem qualquer diferenciação dentro do grupo e $15,38 \%$ fizeram alguma diferenciação entre os mais jovens. Os resultados indicam ainda que 30,77\% dos entrevistados citam algum tipo de deterioração neste ambiente e 38,46\% falam sobre a cobrança nesta fase.

\section{NA SUA OPINIÃO, DEVERIA EXISTIR ALGUMA MUDANÇA NAS COMPETIÇÕES DOS MAIS JOVENS DE JUDÔ?}




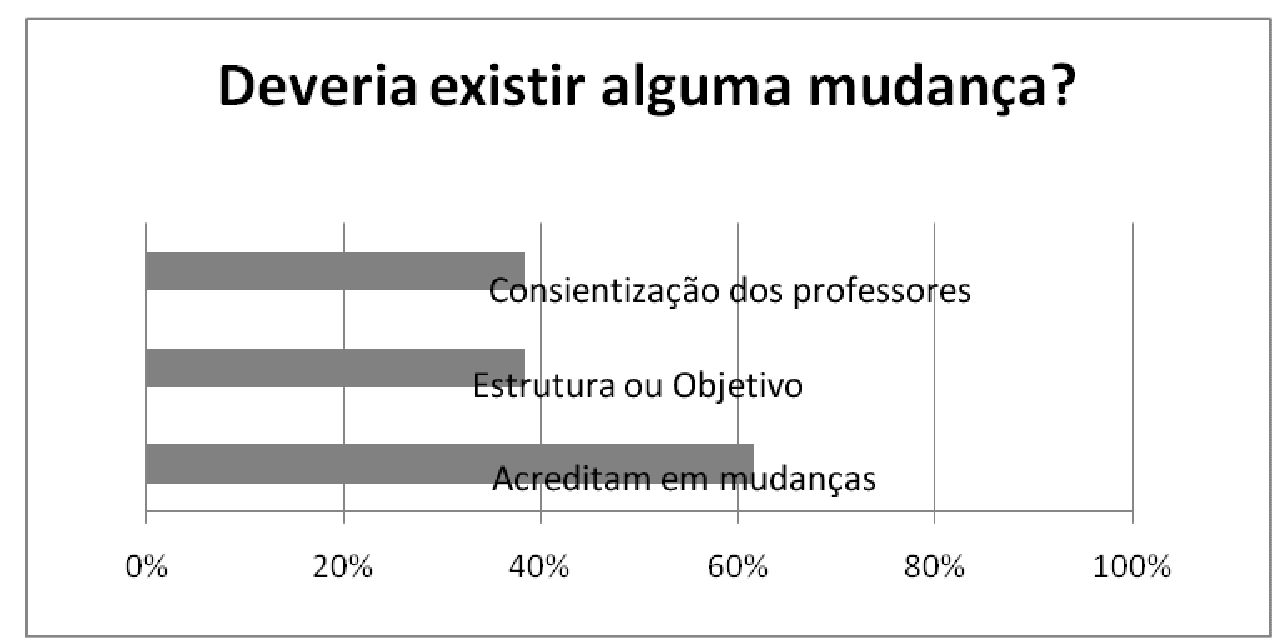

Gráfico 6 - Na sua opinião, deveria existir alguma mudança nas competições dos mais jovens de Judô?

Apesar dessa pergunta não ter sido construída para verificar se os responsáveis acreditam em mudanças, mas sim para constatar a natureza da mudança sugerida, optamos por incluir esse dado no gráfico não pela quantidade dos que acreditam em mudanças (61,53\%), mas, pela quantidade que, mesmo ao serem indagados sobre possíveis mudanças, não acreditam que elas possam ou devam acontecer $(38,46 \%)$.

Obteve-se uma frequência de respostas de 38,46\% dos responsáveis citando modificações a respeito dos objetivos ou da estrutura das competições. $O$ mesmo número de responsáveis aponta a necessidade da conscientização.

\section{PARA QUE SERVEM, QUAL A FINALIDADE, DAS COMPETIÇÕES DE JUDÔ DOS MAIS JOVENS?}

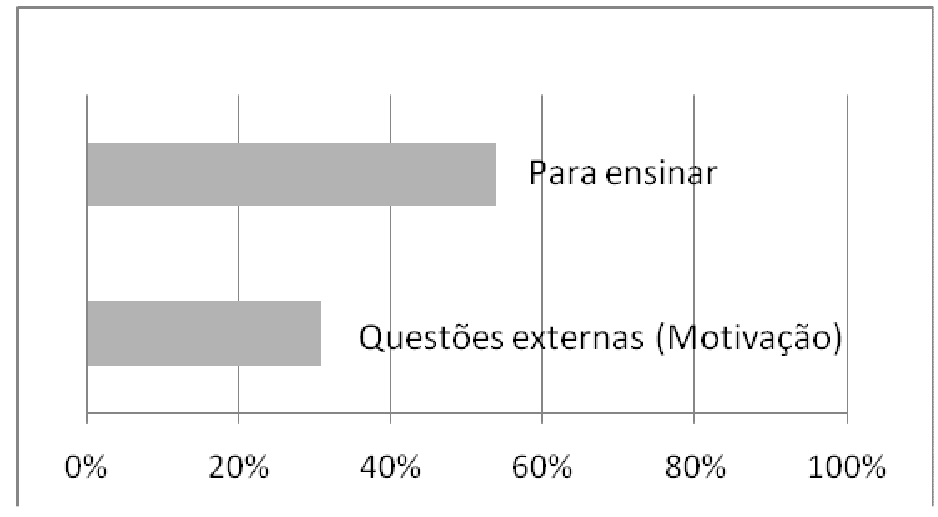

Gráfico 7 - Para que serve, qual a finalidade, das competições dos mais jovens? 
Os dados indicam que 53,85\% dos responsáveis referiram-se à competição como capaz de ensinar algo, seja um valor, seja alguma questão técnica. $30,77 \%$ dos responsáveis citaram questões externas à competição em si, principalmente a motivação. Nesses casos, a competição foi vista não como importante por si só, mas, para motivar a treinar, por exemplo.

\section{DISCUSSÃO}

As interpretações contidas neste artigo têm, como maiores influências, os estudos da sociologia e os estudos pedagógicos sobre o esporte. Estabelece-se, assim, um olhar sensível às condições sociais ao mesmo tempo em que são feitas reflexões educacionais sobre quais os conhecimentos e quais os valores que estão sendo trabalhados nesse ambiente.

Os dados obtidos nos possibilitam entender, com maior profundidade, o fenômeno da competição e o que é fundamental para um melhor aproveitamento educacional dessa prática, sobretudo questionando as implicações do modelo atualmente estabelecido.

Elias (1993) caracteriza o trabalho do sociólogo como uma análise pós facto na qual se tenta determinar uma "linha", uma "evolução", um sentido, mas não um progresso. Procura-se engatar o descontínuo, chega-se a uma interpretação sociológica que só se conhece a posteriori.

Neste sentido, ao perguntarmos sobre o que é o Judô, tínhamos como objetivo entender o significado dessa prática social para os responsáveis, precebeu-se que os significados mais freqüentes foram filosofia de vida e esporte. Diferentes concepções sobre o Judô podem resultar em diferentes práticas pedagógicas. Em análise geral, pudemos perceber como são variados os significados do Judô.

Analisando os dados segundo Elias (1993) podemos encontrar convergências e contradições com os apontamentos do autor. A principal convergência é a reorganização dos símbolos iniciais da arte marcial em esporte, que, de acordo com o autor, em tempos de paz, os costumes se modificariam.

Porém, em segunda análise da teoria, a tendência ao monopólio descrita em sua obra não se concretizaria ou funcionaria de maneira diferente com relação ao significado, pois mesmo que o modelo esportivo seja marcante outros significados ainda emergem. Assim, se por um lado o formato esportivo do Judô torna-se um monopólio, uma forma única de se praticar no mundo todo, por outro os significados atribuídos a essa prática são diversos.

Conexões: revista da Faculdade de Educação Física da UNICAMP, Campinas, v. 8, n. 2, p. 159-173, maio/ago. 2010. 
As raízes do Judô no antigo Jiu-Jitsu, arte marcial japonesa, têm pressupostos técnicos e valores diferentes dos praticados no esporte. Apesar de os candidatos citarem uma deterioração técnica ou de valores, não fazem qualquer ligação disso com o próprio processo de esportivização da modalidade.

Retomando Elias (1993), as práticas sociais evoluem, o que não quer dizer que progridam. As mudanças têm seus custos. Talvez do ponto de vista técnico, os custos sejam o "esquecimento" de práticas relevantes ao processo de sobrevivência em situações de perigo. Já no que tange às questões de valores, teríamos de pensar nas virtudes específicas trabalhadas através das práticas ligadas às artes marciais, ou seja, quais valores se perdem ao se transformar uma prática tradicionalmente regida pelo bushido japonês em uma prática tradicionalmente regida pelo fair play inglês.

Em geral, os voluntários indicaram a competição como algo positivo e educativo, porém, pouco se diferencia a competição do adulto da competição dos mais jovens. Não são feitas reflexões sobre sua estrutura social e significados. Não são descritas possibilidades de modificação em sistema de chaveamento, pontuação, relações pessoais, etc. Esse quadro agrava-se quando se tenta encontrar diferenciações dentre os mais jovens.

Percebe-se, ainda, raras são as respostas que se reflete sobre o modelo de competição, sendo assim, os múltiplos significados citados pelos entrevistados poderiam entrar em contradição com o formato de competição estabelecido, podendo gerar incoerências educacionais, a exemplo das cobranças que surgem na descrição da competição dos mais jovens.

Nessa perspectiva existiriam necessidades educacionais diferenciadas que precisam ser contempladas socialmente no processo competitivo que entenda as consequências pedagógicas dessas práticas. São necessárias propostas capazes de considerar as diferenças entre o objetivo das competições entre adultos e mais jovens, considerando as idades e os ambientes, levando em conta a necessidade de diferentes formatos competitivos.

Na categoria seguinte: "conscientização", cabe refletir sobre a idéia de que apenas conscientização bastaria para resolver os "males" da competição. Bastaria conscientizar: pais, professores, alunos, governantes, dirigentes e assim por diante. Se por um lado é de suma importância que as diversas populações sejam conscientizadas, por outro, é necessário que a estrutura social seja favorável a esse 
processo, seja para a conscientização, seja para prevenir possíveis problemas, sejam educacionais ou de saúde. Ou seja, a estrutura social não deve delegar a responsabilidade do que acontece socialmente apenas à responsabilidade individual.

Em uma estrutura não favorável, somente a conscientização tem um trabalho árduo a ser feito, uma vez que ela tenta agir contra o sistema. Os fatores sociais são importantes em processo educacional que leve em consideração a competição como um elemento que considera a formação do indivíduo.

\section{CONCLUSÃO}

Os responsáveis pelas agremiações em sua maioria descrevem positivamente a competição entre os mais jovens, vendo como finalidades da mesma a motivação, integração, motivos particulares aos atletas e a possibilidade de ensino.

Apesar de a competição aparecer como algo educacional, no discurso dos entrevistados, pouco se fala sobre suas possibilidades específicas para os mais jovens. Ao se estimular os entrevistados a pensar sobre possíveis mudanças, ainda temos uma boa parte dos entrevistados que não acreditam em modificações $(38,46 \%)$, porém, dentre aqueles que acreditam, temos metade do grupo falando sobre mudanças para os mais jovens, indicando certa resistência quanto a modificações, porém, incluindo os mais jovens no "quadro" de modificações.

A competição no estado de São Paulo foi caracterizada com dois principais adjetivos: cobrança e deteriorada. Quase $80 \%$ dos entrevistados não diferenciaram a competição dos adultos e mais jovens.

O discurso dos responsáveis pelas agremiações, ao deixar em segundo plano os mais jovens, pode refletir uma situação social que não leve em consideração suas necessidades educacionais. Além disso, pouco se reflete sobre o modelo de competição e suas conseqüências educacionais.

A maior parte dos voluntários acredita que mudanças nas competições dos mais jovens devem ocorrer, sendo que os objetivos, estrutura e conscientização deveriam ser os alvos das mudanças.

O primeiro passo para uma competição coerente é entender que o processo competitivo da criança pode ser diferente do processo competitivo do adulto, mas, com certeza, apenas essa diferenciação não contemplaria todas as necessidades pedagógicas necessárias à formação dos mais jovens. $\mathrm{O}$ passo

Conexões: revista da Faculdade de Educação Física da UNICAMP, Campinas, v. 8, n. 2, p. 159-173, maio/ago. 2010. 
seguinte seria estabelecermos objetivos e formatos diferentes para cada ambiente, para cada faixa etária, para cada nível competitivo.

\section{REFERÊNCIAS}

B ARDIN, L. Análise de conteúdo. Lisboa: Edições 70, 2002.

BROHM, J. M. Sociología política del deporte. México: Fondo de Cultura Económica, 1982.

CAZETTO, F. F. et al. O jogo como meio: o tecnicismo de cara nova. Efdeportes: revista digital, Buenos Aires, v. 92, n. 10, jan. 2006. Disponível em: http://www.efdeportes.com/efd92/judo.htm. Acesso em: 30 jun. 2008.

CAZETTO, F. F. Ensaio provisório sobre alguns aspetos relevantes para o entendimento tático do judô tendo em vista a formação global do indivíduo. 2004. 160f. Trabalho de Conclusão de Curso (Graduação) - Faculdade de Educação Física, Universidade Estadual de Campinas, Campinas, 2004.

.; PAES, R. R. Análise do judô enquanto um conteúdo da Educação Física. In: CONGRESSO DE INICIAÇÃO CIENTIFICA DA UNICAMP, 12., 2004, Campinas. Anais... Campinas: UNICAMP, 2004. 1 CD-ROM.

CAZETTO, F. F. ; PAES, R. R. Estudo sobre a iniciação esportiva na modalidade de judô. In: CONGRESSO DE INICIAÇÃO CIENTIFICA DA UNICAMP, 13., 2005, Campinas. Anais... Campinas: UNICAMP, 2005. 1 CD-ROM.

ELIAS, N. O processo civilizador: a formação dos estados e civilização. Rio de Janeiro: Zahar, 1993. v. 2.

LAKATOS, E. M.; MARCONI, M. A. Fundamentos de metodologia científica. 3. ed. São Paulo: Atlas, 1995.

RITZ, M. R. C. Qualidade de vida no trabalho: construindo, medindo e validando uma pesquisa. 2000. 96f. Dissertação (Mestrado em qualidade) - Instituto de Matemática, estatística e Computação científica,

FABIANO FILIER CAZETTO

Faculdade de Educação Física, Universidade Estadual de Campinas

PAULO CESAR MONTAGNER

Faculdade de Educação Física, Universidade Estadual de Campinas

Conexões: revista da Faculdade de Educação Física da UNICAMP, Campinas, v. 8, n. 2, p. 159-173, maio/ago. 2010. 


\section{PABLO CHRISTIANO LOLLO}

Faculdade de Engenharia de Alimentos, Universidade Estadual de Campinas

\section{Referência do artigo}

\section{ABNT}

CAZETTO, F. F.; MONTAGNER, P. C.; LOLLO, P. C. A competição de judô dos mais jovens: o discurso dos responsáveis pelas agremiações. Conexões, v. 8, n. 2, p. 159-173, 2010.

\section{APA}

CAZETTO, F. F., MONTAGNER, P. C. \& LOLLO, P. C. (2010). A competição de judô dos mais jovens: o discurso dos responsáveis pelas agremiações. Conexões, 8(2), 159-173.

\section{VANCOUVER}

CAZETTO FF, MONTAGNER PC, LOLLO PC. A competição de judô dos mais jovens: o discurso dos responsáveis pelas agremiações. Conexões, 2010; 8(2): 159-173.

\section{Recebido em: jun./2010}

Aceito para publicação em: jun./2010 